\title{
EL CRITERIO DE TOLERANCIA CERO PARA LA CONTAMINACIÓN DE AVES DE CORRAL EN LA REGULACIÓN EUROPEA
}

\section{THE STANDARD OF ZERO TOLERANCE FOR CONTAMINATION OF POULTRY CARCASSES IN EUROPEAN REGULATION}

Juliana Da Silva Martínez

DOI: https://doi.org/10.37767/2591-3476(2020)26

\section{Comentario a}

A y otros c/ Staatssecretaris van Economische Zaken

Tribunal de Justicia de la Unión Europea

\section{Disponible en}

https://bit.ly/3gc4D5f

\section{RESUMEN:}

Este artículo analiza la sentencia del Tribunal de Justicia de la Unión Europea, del 12 de septiembre de 2019, por la que se constata la aplicabilidad del criterio de "tolerancia cero" para la contaminación de las canales de aves de corral, en el contexto de los alimentos de origen animal, cuyas normas de higiene y de control se encuentran en los Reglamentos europeos n. ${ }^{\circ} 853 / 2004$ y 854/2004, respectivamente. .

\section{ABSTRACT}

This article analyses a preliminary rulling of the European Union Court of Justice, dated 12th September 2019, that confirms the applicability of the "zero tolerance" standard over contamination of poultry carcasses, in the context of animal source food, which hygiene and control standards are found in European Regulations n. ${ }^{\circ}$ 853/2004 y 854/2004, respectively.

PALABRAS CLAVE: Prevención, Salud, Riesgo, Protección, Cooperación.

KEY WORDS: Prevention, Health, Risk, Protection, Cooperation 


\section{Introducción}

Se tratará de analizar la sentencia del Tribunal de Justicia de la Unión Europea, dictada el 12 de septiembre de 2019, sobre una cuestión prejudicial interpretativa interpuesta por el Tribunal de Primera Instancia de Rotterdam. Es una sentencia importante para conocer la interpretación de la Unión Europea en relación con las exigencias de higienización de la carne de animales sacrificados para el consumo, visto que analiza la vigencia o no del criterio de tolerancia cero en el proceso de limpieza de las canales de aves de corral, fase en la que se preparan las canales para su posterior refrigeración. La interpretación del TJUE se da con relación al reglamento europeo n. ${ }^{\circ}$ 853/2004 de higiene de los alimentos de origen animal y el reglamento n. ${ }^{\circ} 854 / 2004$, por el que se establecen normas específicas para la organización de controles oficiales de los productos de origen animal destinados al consumo humano, en el contexto de un litigio entre mataderos de aves de los Países Bajos y el Secretario de Estado.

\section{Antecedentes de hecho}

En unos controles de seguridad alimentaria en mataderos de aves de corral neerlandeses, la Autoridad neerlandesa competente encuentra en la fase final de preparación para el cocinado y anterior a la refrigeración de las canales, canales contaminadas por trazas fecales, materiales del buche y de la bilis de las aves de corral.

Tras el registro de la contaminación, la Autoridad neerlandesa de seguridad de los alimentos elabora informes sobre la incidencia en los que se constata como causa la insuficiencia de las medidas tomadas para evitar la contaminación de las canales en los mataderos, constatando además la vulneración de las reglas de la ley neerlandesa sobre animales, y del Anexo III, Sección II, Capítulo IV, puntos 5 y 8 del Reglamento n. ${ }^{\circ}$ 853/2004. Los siete mataderos de aves inspeccionados son sancionados con una multa administrativa, pero se oponen a la sanción, ya que alegan que el Reglamento europeo no permite la aplicación del criterio de tolerancia cero de la contaminación.

La sentencia resuelve una cuestión prejudicial interpretativa del Reglamento n. ${ }^{\circ}$ 853/2004 por el que se establecen normas para la higiene de los alimentos de origen animal, concretamente sobre el Anexo III, Sección II, Capítulo IV, puntos 5 y 8 del Reglamento; y del Reglamento n. ${ }^{\circ}$ 854/2004 por el que se establecen normas para la organización de controles oficiales de los productos de origen animal destinados al consumo humano, concretamente sobre el Anexo I, Sección I, Capítulo II, parte D, punto 1, del Reglamento.

\section{Alegaciones de las partes}

\section{Los mataderos}

Para los mataderos el Reglamento comunitario no obliga a la aplicación del criterio de tolerancia cero y además alegan que las canales podrían limpiarse también en la fase de refrigeración o incluso en fases posteriores.

Otra de las alegaciones de los mataderos es en relación con el alcance del término "contaminación", consideran que ni las heces, ni el contenido de la ingesta de los animales, son elementos potencialmente contaminantes.

Como último recurso, los mataderos se dirigen en contra de la forma en que se realizó la inspección; según estos las canales solo podían ser inspeccionadas visual y superficialmente. 


\section{El secretario de Estado}

El Secretario de Estado alega que los Reglamentos sí establecen el criterio de "tolerancia cero", no debiendo haber contaminación visible antes de la refrigeración de las canales; alega también que por contaminación debe entenderse las materias fecales, el contenido del buche y de la bilis; por último, sostiene en relación con la forma de la inspección, que debe inspeccionarse no solo la canal superficialmente, sino también internamente.

\section{Las cuestiones prejudiciales}

\section{La segunda cuestión}

La segunda cuestión prejudicial que plantea el Tribunal de $1^{\text {a }}$ Instancia neerlandés, pregunta qué se entiende por contaminación en el contexto de las disposiciones del Anexo III, Sección II, Capítulo IV, puntos 5 y 8, del Reglamento n. ${ }^{\circ}$ 853/2004, que el Secretario de Estado considera vulneradas. En concreto, el Tribunal nacional quiere saber si la contaminación puede ser causada por materiales de la bilis, del buche y materiales fecales, es decir, los materiales que la Autoridad alega en su informe que fueron encontrados en las canales de aves de corral.

EI TJUE entonces interpreta que el término "contaminación" debe entenderse desde una perspectiva amplia, sin ningún tipo de limitación que pueda restringirlo. Por tanto, asegura que el término puede abarcar varios materiales, entre ellos están los restos de la bilis, del buche y de las materias fecales. Para explicarlo, el TJUE luego de hacer un análisis pormenorizado del contenido literal de las disposiciones y de relacionarlas entre ellas, empieza a adentrase en la doctrina de la "tolerancia cero".

\section{A. ¿Qué comprende el concepto de contaminación conforme al Reglamento}

\section{n. ${ }^{\circ} 853 / 2004$ ?}

Al no precisar los elementos contaminantes, el Reglamento debe ser interpretado en relación con otras disposiciones, de forma que se pueda sacar el fin y naturaleza de la norma europea. A pesar de no dar una definición concreta de lo que se pueda entender por contaminación, en el punto 5 del Reglamento citado hay una referencia a los elementos del tubo digestivo. Sobre este punto, el TJUE aboga por una interpretación uniforme que respete el sentido del término, conforme a las versiones que ha recibido en todas las lenguas oficiales de la Unión. Ello es así en respeto al principio de multilingüismo, consagrado en la Carta de los Derechos Fundamentales de la Unión Europea. En concreto, recuerda la sentencia en su punto 38 que conforme reiterada jurisprudencia (Tanzer y Trasper), "las disposiciones de derecho de la unión deben ser interpretadas y aplicadas de modo uniforme a la luz de las versiones en todas las lenguas de la Unión", para casos conflictivos debe acudirse a una interpretación estructural, y en todo caso atendiendo al fin intrínseco de la norma. Al realizar una interpretación uniforme de lo que se pueda entender por "tubo digestivo", el TJUE concluye que el término debe comprenderse en sentido amplio, de forma que alegar la existencia de diferentes traducciones no sirva para restringir el alcance del término y así evitar la responsabilidad de los mataderos. Por tanto, el contenido del buche, de la bilis y las materias fecales sí son contenido del tubo digestivo de las aves de corral, conforme la interpretación del TJUE.

Ahora bien, en relación con el concepto de "contaminación", los mataderos también cuestionan si los materiales de la bilis, del buche y fecales que fueron encontrados en sus canales, también son fuentes de contaminación. Para responderlo, el TJUE a la vista 
de la cuestión prejudicial, acude al art. 2, apartado 1, letra f) de otro Reglamento, de n. ${ }^{\circ}$ 852/2004, según el cual el término contaminación implica la "introducción o presencia de un peligro"; también acude al art. 3, punto 14, del Reglamento n. ${ }^{\circ}$ 178/2002, según el cual es factor de peligro "todo agente biológico químico o físico presente en un alimento o en un pienso, o toda condición biológica química o física de un alimento o un pienso que pueda causar un efecto perjudicial para la salud". Por tanto, conforme a una interpretación estructural y atendiendo a la finalidad de la norma, todas las fuentes de contaminación deben ser tomadas en consideración, sin interpretaciones restrictivas.

Por tanto, se concluye que los términos dan pie a una interpretación bastante amplia de la "contaminación" que prohíbe el Reglamento, de forma que pueda cumplirse la finalidad del Reglamento de proteger a los consumidores de estas carnes de "toda contaminación". Aquí se aprecia el criterio de "tolerancia cero", que toma el legislador de la Unión, ya que, al evitar cualquier tipo de limitación a la obligación de proteger a los consumidores de la contaminación, impone una postura que considera inaceptable e inadmisible cualquier tipo de riesgo a los que puedan estar expuestos los consumidores de la carne en Europa. Se erige así, como bien manifiesta el Abogado general, un alto nivel de protección, con altos estándares de calidad alimentaria. Y, como Reglamento, es una norma directamente aplicable en los ordenamientos jurídicos de todos los Estados de la Unión, sin requerir normas internas de aplicación, y protegida por el principio de primacía del Derecho de la Unión.

\section{La primera y la tercera cuestión}

El tribunal neerlandés pregunta en su primera cuestión si las disposiciones del Anexo III, Sección II, Capítulo IV, puntos 5 y 8 del Reglamento n. ${ }^{\circ}$ 853/2004 pueden ser interpretadas como un mandato de que la canal de ave de corral después de su limpieza y evisceración no presente ningún tipo de contaminación visible, es decir, si el Reglamento impone la regla de la tolerancia cero en tema de higienización de la carne para el consumo humano.

Ante esta pregunta, el TJUE considera que por contaminación debe entenderse la contaminación visible y la invisible, ya que quedó aclarado en la segunda cuestión prejudicial que no se aplica ningún criterio de interpretación restrictiva para entender el término "contaminación".

El TJUE entonces concluye que los mataderos sí deben eliminar toda contaminación de la canal en los procesos anteriores a la refrigeración, despiece y envasado. Por tanto, en tras la limpieza y evisceración el legislador europeo aplica el criterio de la tolerancia cero, es decir, no debe quedar ninguna contaminación visible.

En relación con la tercera cuestión, el tribunal pregunta en qué momento viene la fase de limpieza de las canales, es decir, si viene después de la evisceración o también se puede extender a la fase de la refrigeración y despiece para envasado. Esta pregunta es oportuna, porque los mataderos neerlandeses han sido sancionados precisamente por haber sido encontrada contaminación en sus canales en la fase inmediatamente anterior a la refrigeración, y si el TJUE decide que la limpieza puede darse también en la fase de refrigeración - postura que defiende los mataderos - no se consideraría aplicable el criterio de tolerancia cero.

No obstante, al contrario de dar la razón a los mataderos, los jueces del TJUE se distan- 
cian de la posición de imposibilidad de cumplimiento del criterio de tolerancia cero, que adoptan los mataderos, establecen que la canal debe quedar libre de contaminación tanto visible como invisible y para ello deben tomarse medidas en todas las fases, antes de la refrigeración. Ya en el punto 5 del Reglamento se aclara que "deberán tomarse las medidas oportunas para impedir que durante la evisceración se derrame el contenido del tubo digestivo", es decir, el Reglamento establece la obligatoriedad de evitar la contaminación ya en esta fase. No se establece la obligatoriedad de ausencia de contaminación en la fase de evisceración, lo que se establece es la obligación de tomar medidas para evitarla.

Los magistrados del TJUE determinan entonces que fase de limpieza, conforme al punto 8 , debe efectuarse antes de la refrigeración. Tras esta fase ya no puede quedar contaminación. Por tanto, sí se aplica el criterio de tolerancia cero, pues ya después de la fase de limpieza no puede haber ni contaminación visible ni contaminación invisible.

El legislador europeo busca garantizar un elevado nivel de protección, aplicando el criterio de tolerancia cero. Pero, lejos de exigir la ausencia de contaminación en cada uno de los procesos de preparación de la canal - sería imposible evitar al completo la contaminación en la fase de evisceración - el legislador establece la obligación de aplicar un proceso progresivo y gradual de higienización de la canal, porque además de obligar a evitar la contaminación de la canal en la evisceración, también establece una fase de inspección post mortem tras la evisceración, donde un veterinario examina la canal y selecciona partes aptas y no aptas. Tras estas etapas, viene la fase de limpieza que es cuando debe aplicarse el criterio de tolerancia cero, y donde no debe haber ya ningún tipo de contaminación.

Punto 61: "Por lo tanto, en contra de lo que sostienen las demandantes en el litigio principal, la finalidad de la fase de refrigeración no es limpiar las canales para eliminar toda contaminación visible, sino que consiste, en particular, en frenar la multiplicación de los gérmenes y conservar la carne para continuar la fase de despiece y de envasado en las mejores condiciones".

\section{La cuarta cuestión prejudicial}

La cuarta pregunta es en relación con el Reglamento n. ${ }^{\circ}$ 854/2004, Anexo I, Sección I, Capítulo II, parte D, punto 1. El Tribunal cuestiona si el punto 1 puede interpretarse en el sentido de que permite a la autoridad de control, retirar las canales de la cadena de sacrificio para verificar en la parte interior y exterior de la canal, la presencia de contaminación visible.

Ante esta cuestión el TJUE determina que el inspector dispone de un amplio margen de maniobra a efectos de determinar la presencia o no de contaminación, dado el alto nivel de protección que busca el legislador europeo. Es decir, los medios de examen de las canales son amplios y de libre utilización, libertad que permite a las autoridades realizar examen externo, retirada de las canales de la cadena de sacrificio, inspección de vísceras, tejidos adiposos, cavidades, o toma de muestras, todo ello para proteger la salud de los consumidores ante la detección de potenciales enfermedades. 


\section{V. ¿Por qué se establece un alto nivel de protección?}

Con esta pregunta quizá se pueda adentrar en los motivos que impulsaron al legislador europeo a adoptar un Reglamento con medidas tan exigentes de protección de los consumidores frente al riesgo de contaminación de las canales.

El Reglamento n. ${ }^{\circ}$ 853/2004 es una refundición de normas de higiene que la Unión Europa ha ido elaborando en varias directivas destinadas a regular las normas de higiene de los productos de origen animal. El Reglamento, como bien se aclara en su punto 11, no está destinado a regular la manipulación doméstica de los productos, sino que va dirigido a empresas de suministro alimentario de origen animal al por mayor. Al armonizar las directivas en un Reglamento, el legislador consigue reforzar el nivel de protección a los consumidores, ya que las normas de higiene ya no dependen del desarrollo normativo de cada Estado miembro, sino que los Estados tienen que aplicar el reglamento de forma directa. Al estar ante un tema tan importante como es el de la salud pública, el legislador decide no dejar el tema de regulación de las normas de higiene a merced del desarrollo normativo de cada Estado miembro.

En el año 2000, cuatro años antes de la publicación del Reglamento, el Tratado de Niza proclama la Carta de los Derechos Fundamentales de la Unión Europea, que no tiene valor jurídico vinculante en este momento, aunque se empiezan a notar sus efectos, en regulaciones como la del Reglamento citado. Y es que la Carta en su artículo 35 introduce el derecho de protección a la salud, subrayando la meta común de la Unión, de garantizar un elevado nivel de protección de la salud humana.

\section{Historial epidémico mundial}

El historial de enfermedades alrededor del año 2004 también tiene mucho que ver en la regulación europea. Conforme datos de la Organización Mundial de la Salud (OMS), el brote del SARS-CoV - un virus perteneciente a la familia del coronavirus - afectó en 2003 más de 8 mil personas en todo el mundo; también en el 2003, el virus H5N1 - más conocido como gripe aviar y potencialmente peligroso para el ser humano debido a su alta contagiosidad entre las aves - afecta a miles de aves de corral y obliga a su sacrificio para evitar el contagio de la enfermedad a los seres humanos; también en el año 2003 en un comunicado de prensa la OMS reconoce que la "enfermedad de las vacas locas" era hasta entonces una enfermedad de reciente aparición y cuyo contagio probablemente se daba al consumir carne de vacuno infectada.

Todas estas enfermedades alertadas por la OMS en el año 2003 tienen un elemento en común: son de origen animal. Por tanto, es comprensible que Europa endureciera los requisitos de higiene de la carne destinada al consumo.

\section{El criterio de tolerancia cero, un precedente: Estados Unidos}

Según el informe del Servicio de Investigación del Congreso de Estados Unidos (2005), el criterio o estándar de tolerancia cero conforma una política de seguridad alimentaria que en Estados Unidos implica generalmente la prohibición de la presencia de materias fecales visibles en las canales de aves de corral o carne. El informe también explica que en la política de seguridad alimentaria si un producto está afectado por una materia microbiológica, química u otra perjudicial para la salud humana, el producto es inmediatamente considerado inadecuado para el consumo. 
Según este mismo informe el Departamento de Agricultura de los Estados Unidos ya confirmó en el año 1997 la aplicación del criterio de tolerancia cero para el procesamiento de canales de aves de corral en los mataderos. Con ello el departamento quiso reforzar que en las canales no debería haber ningún signo de heces o de contaminación microbiológica antes de la fase de refrigeración.

Además, según las directivas más actuales del Servicio de Inspección Alimentaria de Estados Unidos (FSIS) se señala constantemente a las heces, a los elementos del tracto intestinal y a la leche como sustancias contaminantes a las que se les debe aplicar un criterio de tolerancia cero, es decir, debe comprobarse que no estén presentes y debe garantizarse de que sean correctamente retirados en caso de que lo estén.

Según las directivas del Servicio de Inspección Alimentaria de Estados unidos la aplicación del criterio de tolerancia cero es obligatoria en los mataderos de aves de corral. El organismo establece la prohibición de contaminación fecal visible en las canales, y la inspección de estas antes de la fase de refrigeración. El organismo reconoce que la presencia de heces en las canales puede provocar la proliferación de patógenos perjudiciales para la salud humana, además también obliga a la implementación de normas del Análisis de Peligros y Puntos de Control Crítico (HACCP) en orden de evitar el contagio microbiológico de las canales, principalmente el contagio por Salmonella. Ahora bien, la contaminación fecal debe ser retirada por completo, sea por lavado químico o cortando las zonas infectadas. EI FSIS también reconoce que los elementos del tracto digestivo pueden ser fuente de patógenos, y por tanto las canales contaminadas por esos materiales del tracto también deben ser reprocesadas.

Las normas o principios HACCP fueron ideadas por la empresa Pillsbury Company, en el año $1971^{2}$. Se trata de un sistema de control de calidad de los alimentos, que tiene como objetivo garantizar su máxima inocuidad. Fue elaborado en principio para evitar introducir alimentos contaminados en las naves espaciales americanas y así evitar la contaminación de los astronautas que hacían parte del programa espacial americano.

En español estos principios se conocen como sistema de Análisis de Peligros y Puntos de Control Crítico (APPCC). El Reglamento europeo 852/2004 sobre la higiene de los productos alimenticios, en el considerando (12), establece la obligatoriedad de aplicar el sistema de principios APPCC para la seguridad alimentaria. También el artículo 4 del Reglamento $854 / 2004$ establece que los controles oficiales de seguridad alimentaria deben orientarse en procedimientos del sistema de análisis de peligros y puntos de control (APPCC).

\section{Crítica}

Los Reglamentos n. ${ }^{\circ} 853 / 2004$ y n. ${ }^{\circ} 854 / 2004$ fueron elaborados cuando el término "tolerancia cero" ya era usado ampliamente en los Estados Unidos. Europa, aunque establece unos estándares y un nivel de protección similar a los que ya estaban en vigor en Estados Unidos, opta por no incluir el término "tolerancia cero" en el Reglamento, dejando apertura a interpretaciones de diferentes grados alrededor de la aplicabilidad o no del criterio.

La seguridad alimentaria en Europa también tambalea a niveles normativos, al no incluir una definición más precisa de lo que pueda entenderse por contaminación, abriendo vía 
a la posibilidad de debatir un tema que debería ser indiscutible: la seguridad alimentaria. La más mínima posibilidad de aflojar las reglas de seguridad alimentaria no debería ni siquiera permitirse cuando alcanzar un alto nivel de protección de la salud pública es una prioridad.

Todo ello culmina en que la normativa europea termina por obligar al Juez europeo a enredarse en un entramado de disposiciones, y conexiones imprecisas, para probar que el concepto de "contaminación" es amplio y puede entenderse desde varios sentidos, o para probar que sí se aplica el criterio de la tolerancia cero en Europa y así garantizar el alto nivel de protección a la salud.

\section{Conclusiones}

La sentencia sienta en Europa la doctrina de la "tolerancia cero" para las sustancias contaminantes de canales de aves de corral, que puede incluso extenderse analógicamente y teniendo en cuenta el contexto de la normativa europea, a los demás alimentos de origen animal. Es importante un reconocimiento jurisprudencial a nivel europeo de este criterio en el sector alimentario, ya que refuerza la normativa europea a escala de todos los países de la Unión, siendo también de interés para terceros países importadores debido a la incidencia y a las consecuencias que puede tener el consumo de alimentos de origen animal importados de Europa - y exportadores. Aunque el reconocimiento de este criterio llega de forma un tanto tardía en Europa, y con una normativa un tanto enrevesada.

\section{REFERENCIAS BIBLIOGRÁFICAS}

- Congressional Research Service. The Library of Congress (2005). Agriculture: A Glossary of Terms, Programs, and Laws (97-905). Recuperado de: http://ncseonline.org/nle/ crsreports/05jun/97-905.pdf

- Directiva 6420.2 Rev. 1, Departamento Estadounidense de Agricultura. Servicio de Inspección Alimentario de Seguridad (FSIS). Estados Unidos, 27 de abril de 2017.

- Rasekh, J., Thaler, A. M., Englejohn, D. L., \& Pihkala, N. H. (2005, 1 octubre). Food Safety and Inspection Service Policy for Control of Poultry Contaminated by Digestive Tract Contents: A Review. Recuperado de https://www.sciencedirect.com/science/article/pii/ S1056617119318471

-Sanchez,J. D.(s.f.). Historia del Sistema HACCP. Recuperado 12 de julio de 2020, de https:// www.paho.org/hq/index.php?option=com_content\&view=article\&id=10833:2015-historia-sistemahaccp\&ltemid=41432\&lang=es\#:\%7E:text=La\%20Pillsbury\%20Company\%20 present\%C3\%B3\%20el,alimentos\%20enlatados\%20de\%20baja\%20acidez.

- World Health Organization. (2013, 9 julio). OMS, 2004. Recuperado de https://www.who. int/csr/don/archive/year/2004/es/ 